\author{
Military Technical College \\ Kobry El-Kobbah, \\ Cairo, Egypt.
}

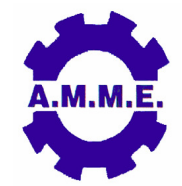

\title{
AMORPHIZATION OF TITANIUM AFTER SURFACE MECHANICAL ATTRITION TREATMENT
}

\author{
A. E. Hannora ${ }^{1}$ and E. M. Duraia ${ }^{2}$
}

\begin{abstract}
Titanium substrates were subjected to severe plastic deformation using surface mechanical attrition treatment (SMAT) in a high energy ball mill. It is demonstrated that different mechanical treatments influence the microstructural and mechanical behaviour of the Ti-surface; moreover, solid state amorphization takes place. Amorphization take place concurrently in the surface region, and successive subdivision and amorphization finally result in the formation of well separated nanocrystalline and amorphous phases in the near surface. The average grain size of the nanocrystallites is about $\sim 200 \mathrm{~nm}$ after 10 min of SMAT while $\sim 18 \mathrm{~nm}$ after 20 $\min$.
\end{abstract}

Surface mechanically treatment of Ti-substrates were characterized by the X-Ray Diffraction (XRD) and scanning probe microscope (SPM) using atomic force microscopy (AFM). The microhardness of the mechanically treated Ti-surfaces is improved as a result of surface nanocrystallization.

\section{KEY WORDS}

Titanium, surface mechanical attrition treatment, surface nanocrystallization, solid state amorphization, microhardness.

1 Suez Canal University, Faculty of Petroleum and Mining Engineering, Engineering Science and Mathematics Department, Suez, Egypt, 43721.

2 Suez Canal University, Faculty of Science, Physics Department, Ismailia, Egypt. 


\section{INTRODUCTION}

The commercially pure titanium (CP $\mathrm{Ti}$ ) is chemically inert and biologically more compatible than $\mathrm{Ti}-6 \mathrm{Al}-4 \mathrm{~V}$, but coarse-grained $\mathrm{Ti}$ has low wear and abrasion resistance because of its low hardness. Most failures of materials occurring on surfaces (fatigue fracture, fretting fatigue, wear and corrosion etc.) are very sensitive to the surface structure and properties, so that surface-optimization may effectively enhance the overall properties of materials [1-3]. The surface mechanical attrition treatment technique involves repeated multidirectional impacts by flying balls to induce surface hardening of bulk samples. The impacts cause severe plastic deformation in the surface layer of the treated sample, leading to grain refinement and large grain boundary misorientation, dislocation blocks and microbands [2-5]. Recent investigations have demonstrated that commercially pure titanium with an ultrafine grain structure in the nanometer range can be processed using severe plastic deformation methods such as equal channel angular pressing and high pressure torsion [3]. The SMAT process has been successfully applied to various material systems [4-6].

The formation mechanism of nanocrystalline structures in a variety of materials during severe plastic deformation has also been investigated and it is generally recognized that the dislocation activities and mechanical twinning dominate the grain refinement mechanism in many nanocrystalline metals [6]. Amorphisation reactions by ball milling/alloying have been studied for a wide number of systems [7]. However, to the best of our knowledge, no systematical work has been conducted in order to elucidate the underlying mechanism associated with commercial $\mathrm{Ti}$ amorphization by SMAT method. So the objective of this work is to study the effects of surface mechanical treatment on the microstructure and microhardness of occurs in commercially pure titanium during the SMAT process.

\section{MATERIALS AND METHODS}

The surface mechanical treatment of the Ti-substrate was carried out using a high energy vibrating ball mill. The hardened steel cylindrical milling vial $\left(20 \mathrm{~cm}^{3}\right)$ vibrate vertically by mechano-reactor with frequency $85 \mathrm{~Hz}$ and amplitude $13 \mathrm{~mm} .1 / 3$ of the total volume of the container was filled with a large number of hardened steel milling balls ( 3, 5 and $6.3 \mathrm{~mm}$ in diameter). Prior to SMAT, specimens machined from the bar were surface-polished with silicon carbide paper to grade 600.The SMAT process was carried out in static air without process control agent. The chamber was just O-ring sealed in order to prevent contamination from the atmosphere. For optical microscopy investigation the cross section of the substrates was prepared according to the standard metallography preparation by embedding in epoxy, grinding, carefully mechanical polishing and etching with bakers reagent that consists of $96 \mathrm{ml}$ distilled water, $2 \mathrm{ml} \mathrm{HF}$ and $2 \mathrm{ml} \mathrm{HNO}_{3}$.

XRD patterns data through the process of surface mechanical treatment are essential to follow and understanding mechanism of microstructure transformation. XRD was performed using D5000 powder diffractometer using $\mathrm{Cu} \mathrm{K}_{\alpha}$ radiation (wavelength $\lambda=0.15406 \mathrm{~nm}$ ) with a nickel filter at $40 \mathrm{kV}$ and $30 \mathrm{~mA}$. The 
diffractometer was operated with step-time $=3$ seconds and step-size $=0.02$ degree. Diffraction signal intensity throughout the scan was monitored and processed with DIFFRACplus software. The surface topography of the titanium samples was examined with scanning probe microscope (SPM) using atomic force microscopy (AFM). Vicker's hardness was determined on the large surface of the Ti substrates using 200gm load in Vickers hardness testing machine. Five measurements were taken on each surface of the substrate and the average was considered at room temperature.

\section{RESULTS AND DISCUSSION}

Figure 1 shows the XRD patterns in the top layer of the SMAT samples processed for various time. With increasing SMAT time, the XRD patterns shows a notable broadening and intensity reduction for (100), (002) and (101) peaks. However, the (002) peak shows intensity reduction much more the other two peaks. Hu el al. [6] showed that, the multi-directional impacts in SMAT may change the slip system with strain path even inside the same grain. The Ti-peaks were completely diapers after 40 min of the surface treatment which is an indicator of a possible deformation induced solid state amorphization.

It is found that at low strains, twinning can contribute significantly to accommodation of the deformation. Twinning can accommodate only a portion of the plastic strains in the fan-shaped deformation zone. Even in this zone, a significant portion of the strains are expected to be accommodated by dislocation slip resulting in some refinement of the microstructure [8]. Ti has an hcp crystal structure with a $\{10 \overline{10}\}(11 \overline{2} 0)$ slip system at room temperature. Its slip systems changes to $\{0001\}\langle 11 \overline{2} 0)$ at the temperature range $\left(400-450^{\circ} \mathrm{C}\right)$ of Equal channel angular pressing processing used in this investigation [9]. Generally the number of slip systems - which is equivalent to the number of dislocation glide opportunities in a crystal lattice - is only 3 for the hcp structure. The denser slip planes are packed with atoms, the easier dislocations can glide [10]. The XRD patterns of Fig. 2 indicate the presence of amorphous phase after $40 \mathrm{~min}$. Additionally the XRD patterns confirm that after higher milling time, $120 \mathrm{~min}$, no new phases, oxides, were found through the SMAT process.

A general view of the Ti substrate before treatment can be inferred from optical microscopy images taken on the surface (Fig. 3). As seen, the microstructure consists of coarse grains with average grain size $\sim 35 \mu \mathrm{m}$. After SMAT for only 10 min, the large grains disappeared and identification of the microstructure becomes very difficult using optical microscopy. Through the SMAT process the titanium sample shows surface deformation as a result of impaction, figure 4 .

Figure 5 presents a typical surface morphology of titanium substrate in the initial state before surface mechanical treatment obtained by optical. After $10 \mathrm{~min}$ of SMAT, the AFM results shows that, the grain size of the titanium sample reduces sharply to less than $\sim 200 \mathrm{~nm}$ and it was $18 \mathrm{~nm}$ after $20 \mathrm{~min}$. While Zhu et al. [3] showed that the microstructure is composed mainly of $100-300 \mathrm{~nm}$ equiaxed nanograins after 60 min using spherical shots by high-power ultrasound $(20 \mathrm{kHz})$. The microstructure of the Ti-substrate shows that with increasing SMAT time the 
amount of accumulated deformation affect the structural elements (grains /subgrains) and causes grain reduction. As the strain increases the scale of the microstructure reduce very rapidly, this could be due to the further formation of twins. Also, additional strain accommodation is achieved by successive grain subdivision. Additional severe plastic deformation to the deformed Ti surface transform grains and subgrains into amorphous can be shown in Fig. 6. As the SMAT time increases the average roughness $\left(R_{a}\right)$ of the Ti surface increased relatively, table 1 . The reduction of $R_{a}$ after 60 min could be due to inhomogeneity of the surface roughness at this small area of scan $(50 \mu \mathrm{m})$.

According to $\mathrm{Hu}$ et al. [6] in the case of amorphization under mechanical driving forces, plastic deformation-induced defects such as point defects, dislocations, twins, sub-boundaries, etc. are responsible for raising the free energy of the crystalline alloy to above that of the amorphous counterpart. So the stored energy only contributes to partial amorphization of the Ti surface. At the same time, grain refinement during SMAT provides a large volume of nanocrystalline and ultrafine grains, in which the grain boundaries significantly increase the stored energy. The twinning formatting and grain boundaries contribute significantly to the crystalline-toamorphous transformation in $\mathrm{Ti}$ surface. Therefore, the energy stored in grain boundaries can drive the crystalline-to-amorphous transformation.

Table 1. Roughness of Ti-samples after surface mechanical attrition treatment.

\begin{tabular}{|l|c|c|c|c|c|}
\hline SMAT Time $(\mathrm{min})$ & 0 & 40 & 60 & 90 & 120 \\
\hline Surface Roughness $(\mu \mathrm{m})$ & 0.5 & 1.2 & 0.9 & 1.4 & 3.5 \\
\hline
\end{tabular}

In order to investigate the effect of mechanical treatment on the mechanical properties of the Ti-substrates, conventional Vickers microhardness was used. The mean value of the Vickers microhardness $(\mathrm{Hv})$ as averaged from 5 different tests, at room temperature. As hardness properties are basically related to the crystal structure of the material, hardness studies are carried to understand the plasticity of the crystal [11]. After severe plastic deformation by SMAT, a noticeable refinement in the microstructure of titanium also occurs along with a marked change of mechanical properties. It is seen that mechanical treatment leads to a selective enhancement surface microhardness measurements, figure 7.

\section{CONCLUSION}

Severe plastic deformation during SMAT produces nanocrystalline and amorphous phases in the surface region of the Ti-surface. As the strain increase due to surface impaction, the stress induces twinning formation. As the heavy deformation is introduced by the impacting balls, the amorphous $\mathrm{Ti}$ surface region becomes considerably harder. 


\section{REFERENCE}

[1] Wen M., Liu G., Gu J., Guan W., Lu J.,"Dislocation evolution in titanium during surface severe plastic deformation", Applied Surface Science, No.255, PP6097-6102, (2009).

[2] Révész Á., Szommer P., Szabó P.J., Varga L.K., "Microstructure and morphology of $\mathrm{Cu}-\mathrm{Zr}-\mathrm{Ti}$ coatings produced by thermal spray and treated by surface mechanical attrition", Journal of Alloys and Compounds, No.509S, PP S482-S485, (2011).

[3] Zhu K.Y., Vassel A., Brisset F., Lu K., Lu J., "Nanostructure formation mechanism of a-titanium using SMAT", Acta Materialia, No.52, PP 41004110, (2004).

[4] Laouar L., Hamadache H., Saad S., Bouchelaghem A., Mekhilef S., "Mechanical surface treatment of steel-Optimization parameters of regime", Physics Procedia, No.2,PP 1213-1221, (2009).

[5] Arifvianto B., Suyitno, Mahardika M., Dewo P., Iswanto P.T., Salim U.A., "Effect of surface mechanical attrition treatment (SMAT) on microhardness, surface roughness and wettability of AISI 316L.", Materials Chemistry and Physics, No.125, PP 418-426, (2011).

[6] T. Hu, C.L. Chu, S.L. Wu, R.Z. Xu, G.Y. Sun, T.F. Hung, K.W.K. Yeung, Z.W. Wu, G.Y. Li, Paul K. Chu. "Microstructural evolution in NiTi alloy subjected to surface mechanical attrition treatment and mechanism." Intermetallics 19, PP1136-1145, (2011).

[7] Gonzalez G., Sagarzazu A., Bonyuet D., Angelo L. D', Villalba R., "Solid state amorphisation in binary systems prepared by mechanical alloying", Journal of Alloys and Compounds, No.483, PP 289-297, (2009).

[8] Ravi Shankar M., Rao B.C., Lee S., Chandrasekar S., King A. H., Dale Compton W. "Severe plastic deformation (SPD) of titanium at near-ambient temperature." Acta Materialia, No.54, PP3691-3700, (2006).

[9] Vladimir V. Stolyarov, Y. Theodore Zhu, Igor V. Alexandrov, Terry C. Lowe, Ruslan Z. Valiev., "Influence of ECAP routes on the microstructure and properties of pure Ti.", Materials Science and Engineering A, No.299, PP 5967, (2001).

[10] Leyens C., Peters M. Titanium and Titanium Alloys. Weinheim: WILEY-VCH Verlag GmbH \& Co. KGaA, 2003.

[11] Karan S., Sen Gupta S., Sen Gupta S.P., "Microhardness and its related physical constants in solution-grown ammonium sulphate single crystals.", Materials Chemistry and Physics, No.69, PP 143-147, (2001). 


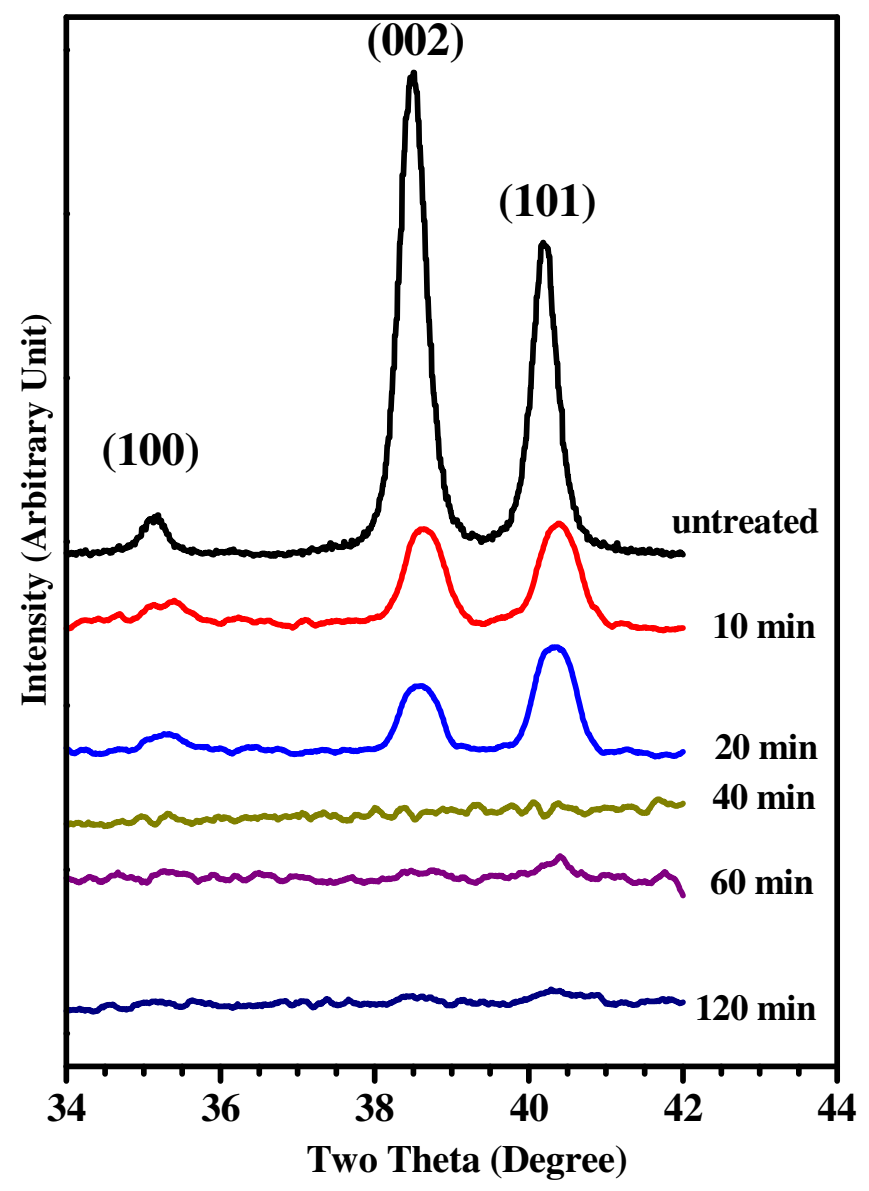

Fig.1. XRD patterns of surface mechanical treatment Ti-substrate with time.

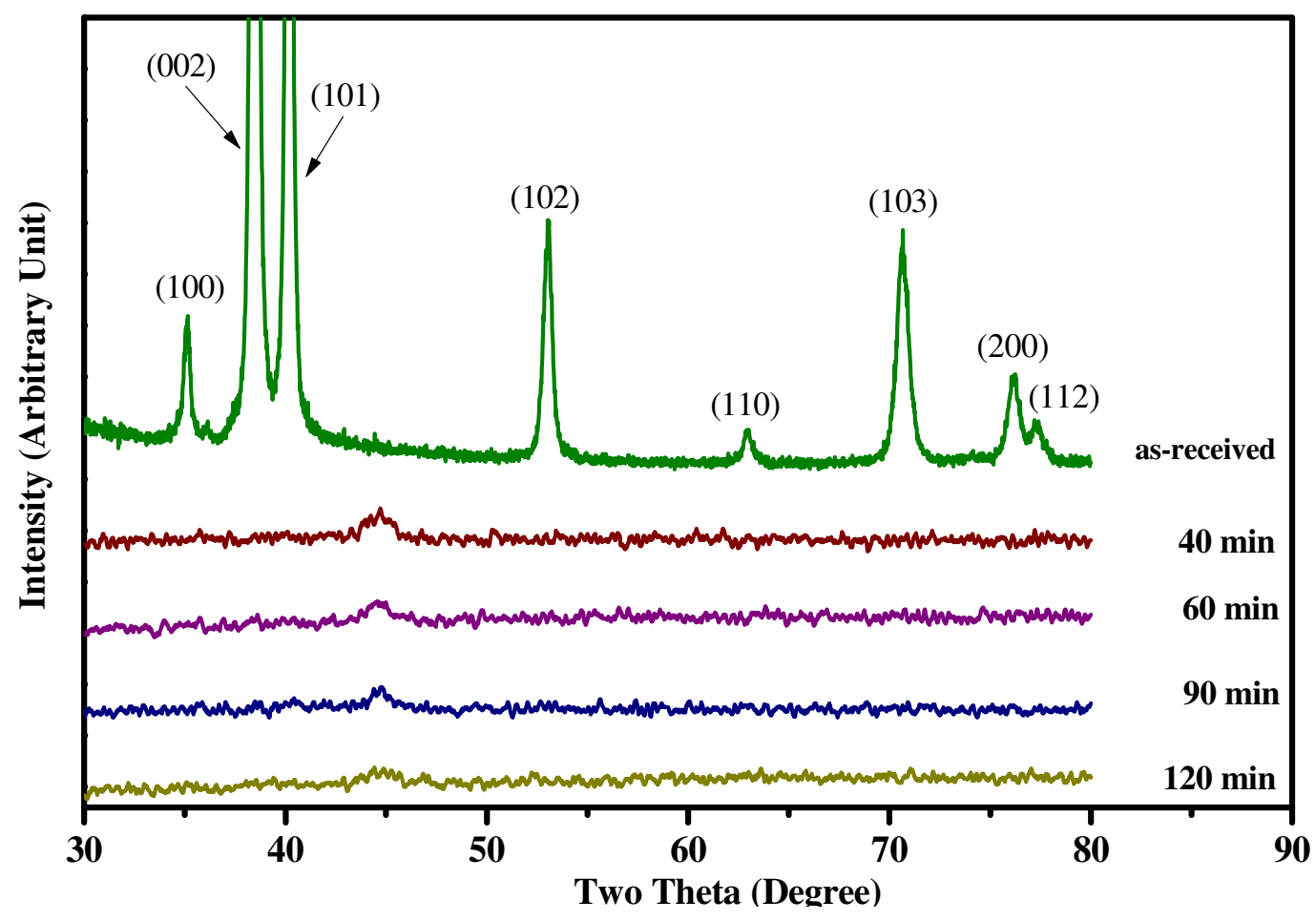

Fig.2. Amorphization of Ti-substrate after surface mechanical treatment. 


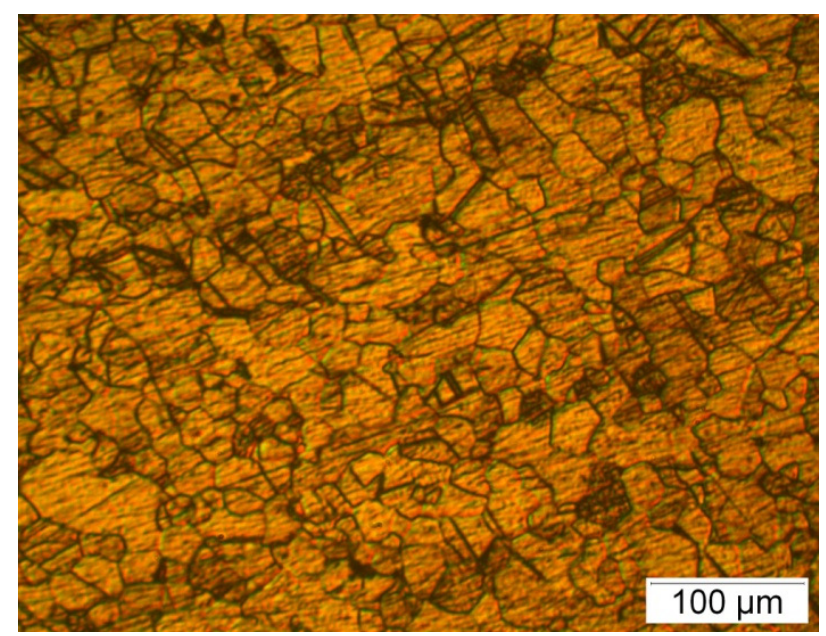

Fig.3. Optical Microscopy of Ti-substrate before surface mechanical treatment.
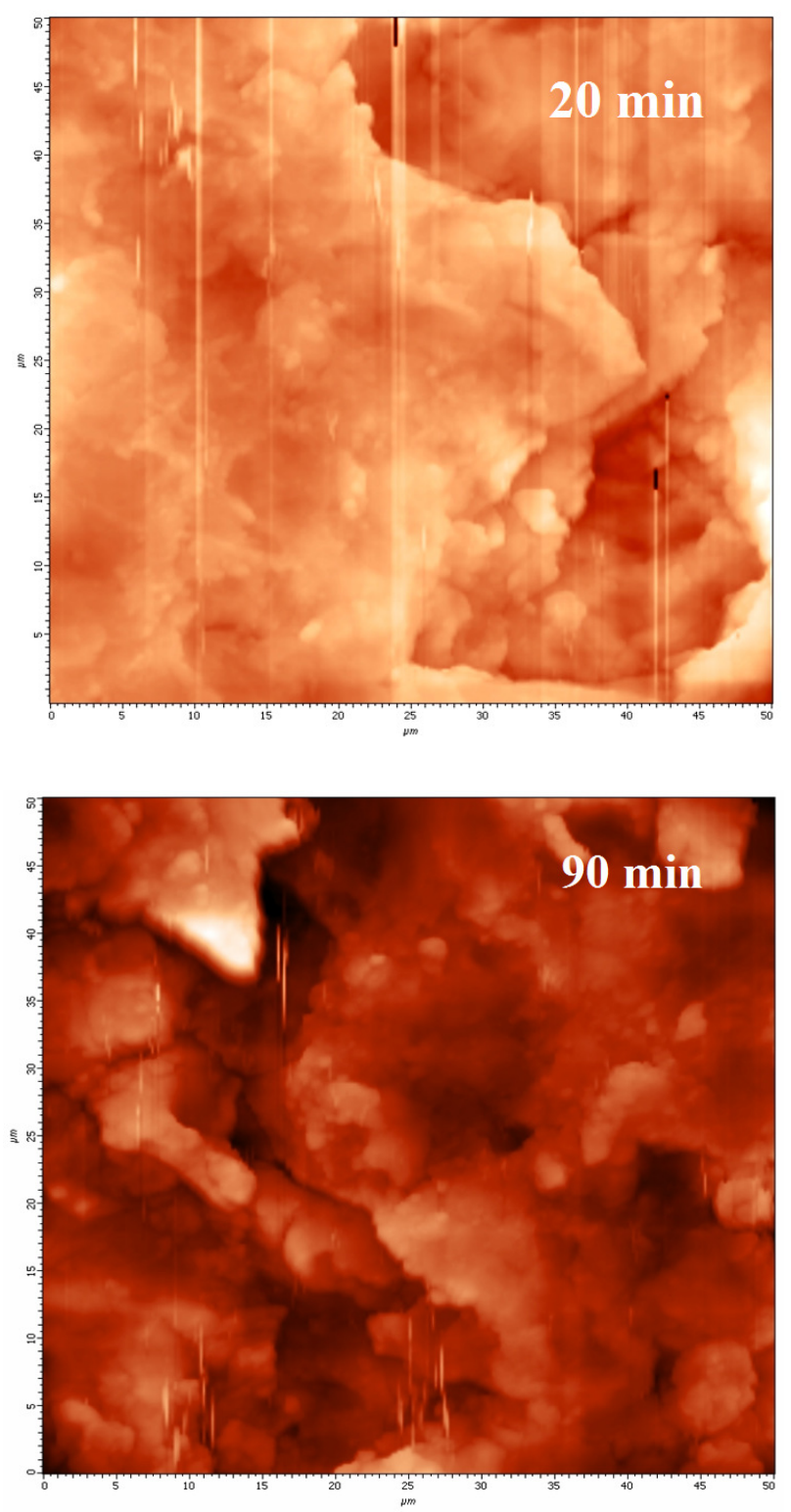

Fig.4. AFM of titanium substrate after of SMAT. 

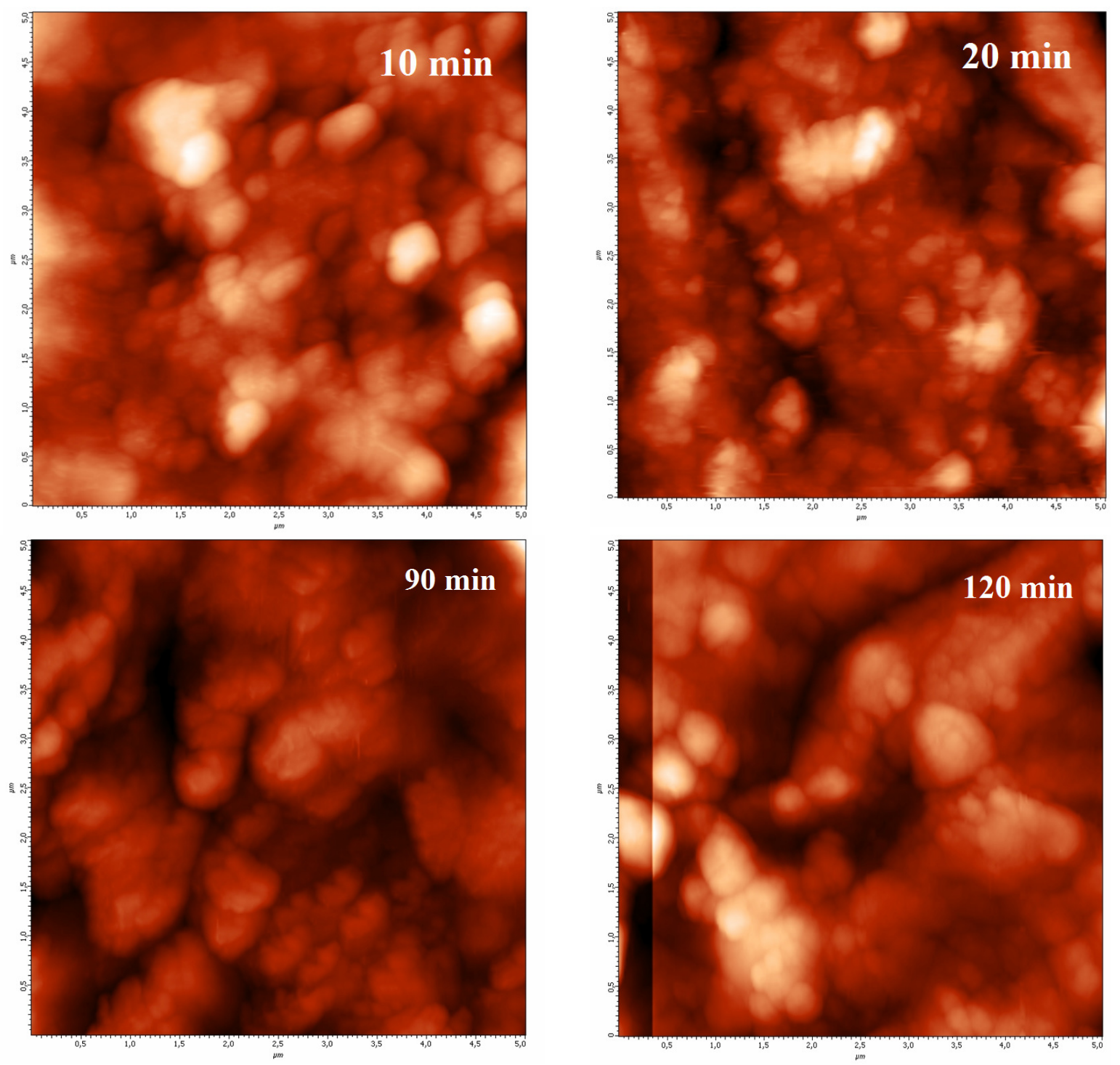

Fig.5. AFM of titanium substrate after SMAT as a function of time.
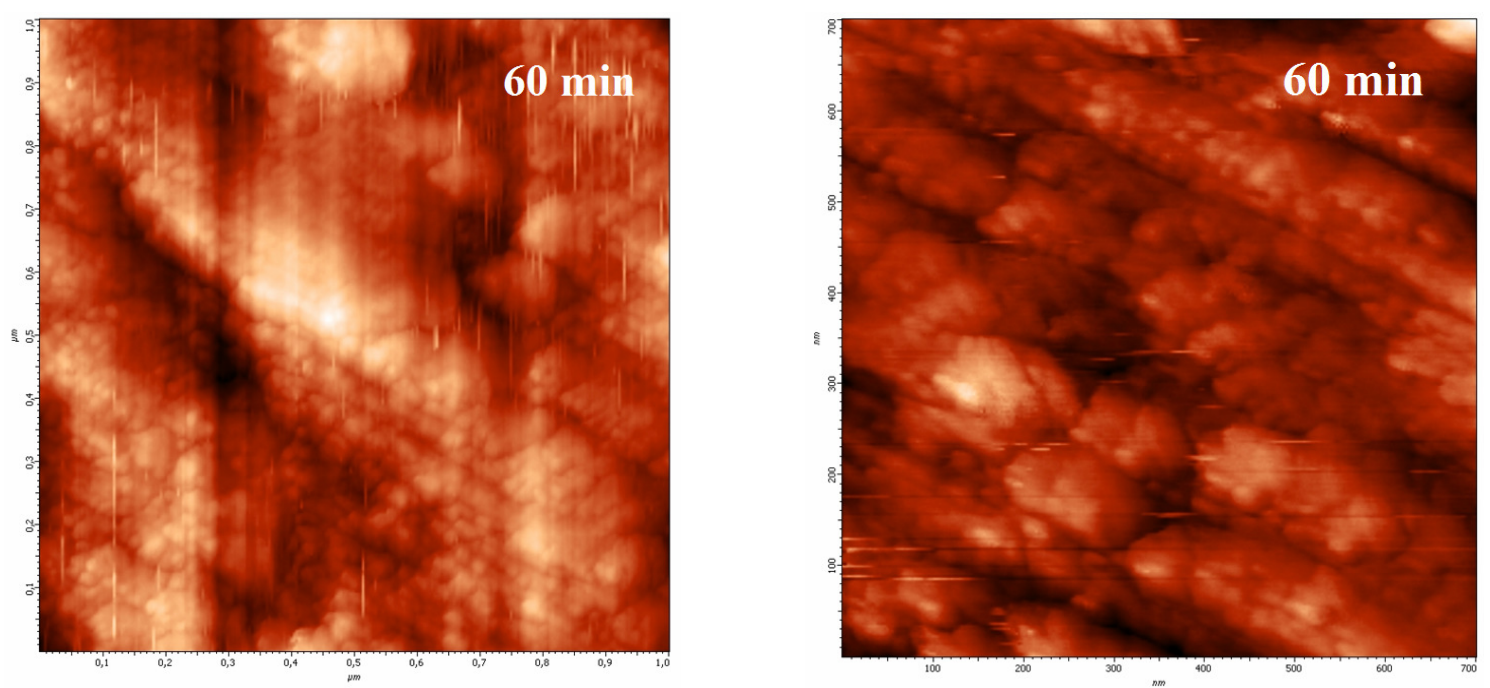

Fig.6. AFM of titanium substrate after 60 min of SMAT. 


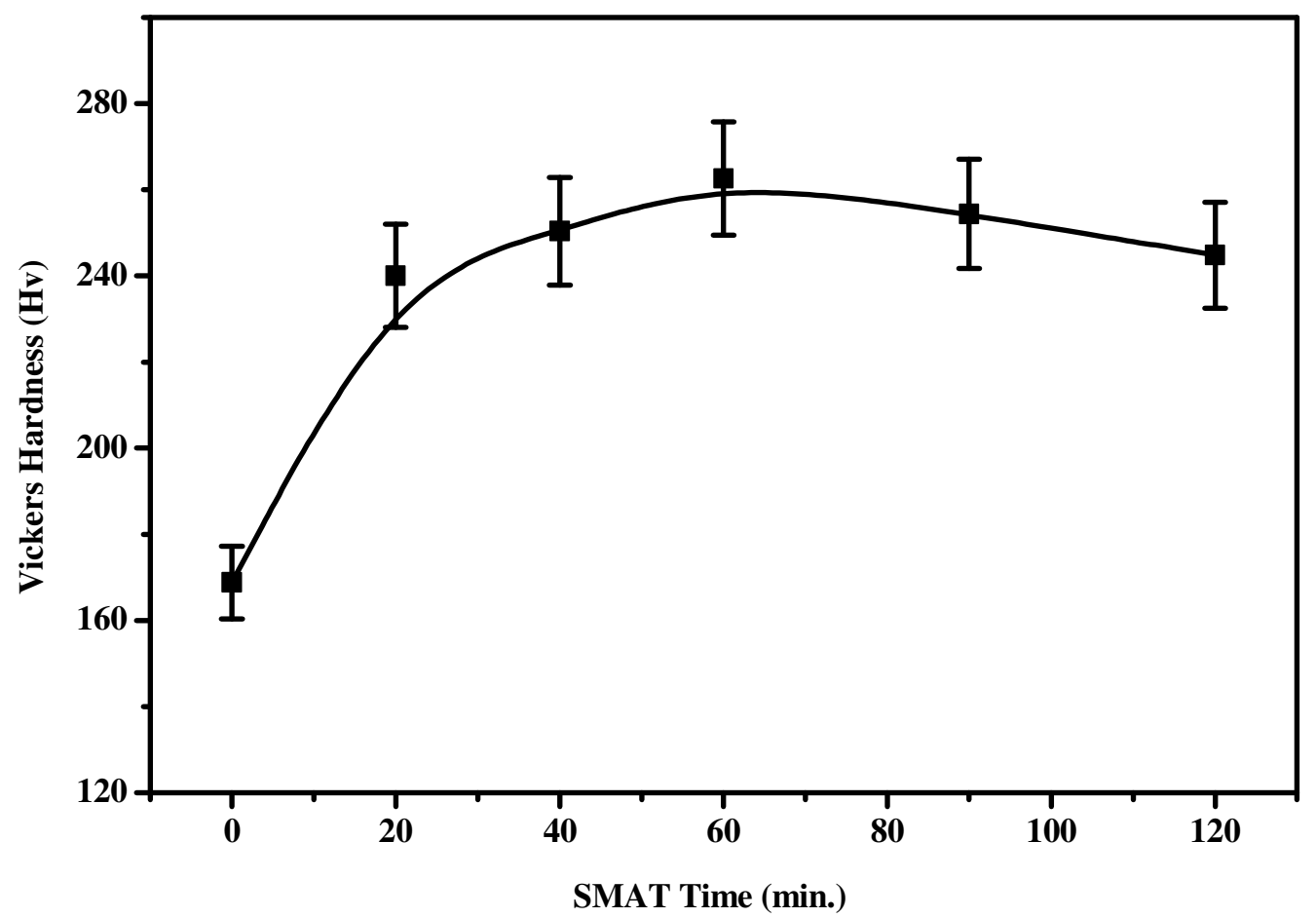

Fig.7. Variation of titanium microhardness with surface mechanical treatment time. 